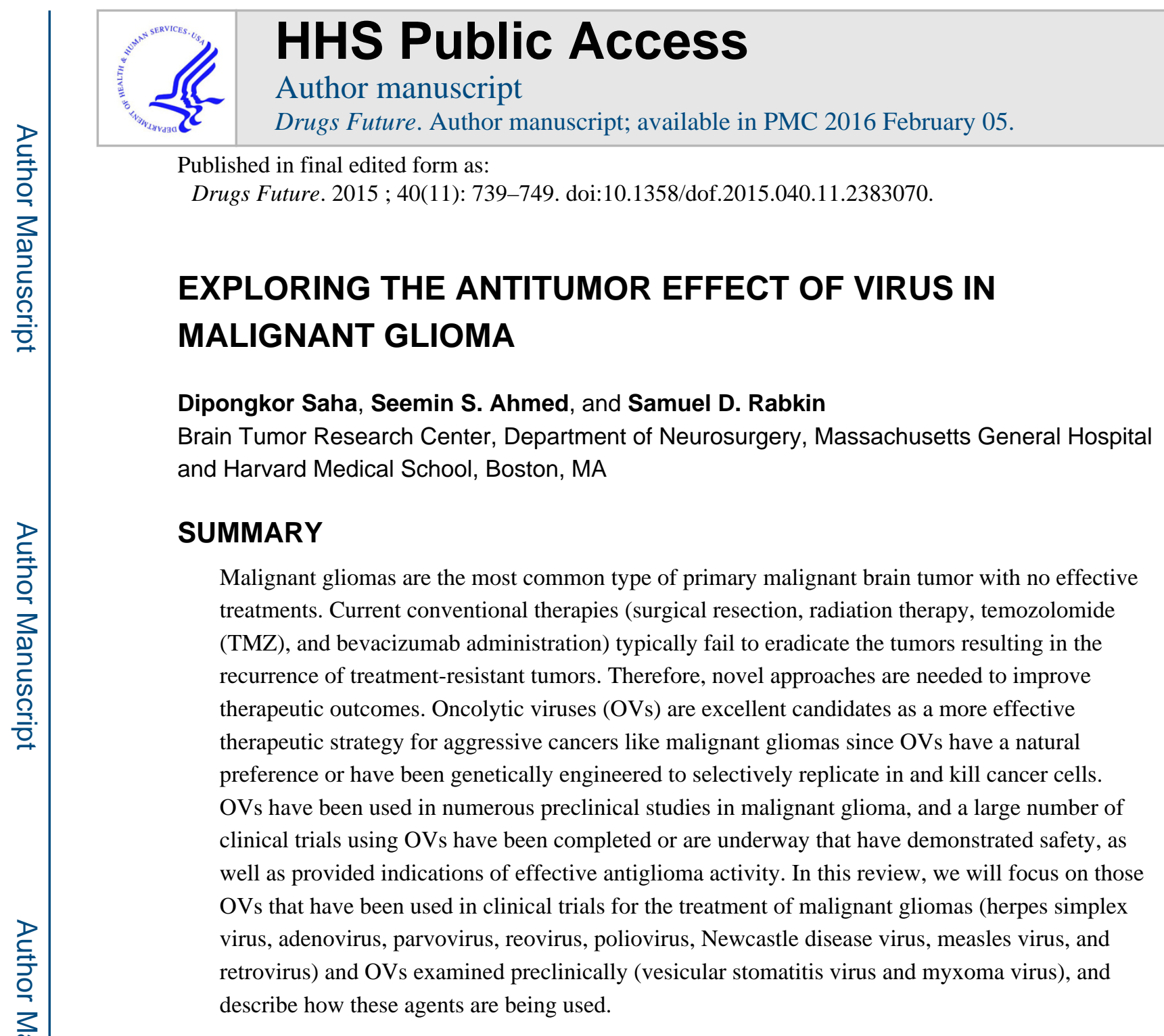

\title{
MALIGNANT GLIOMA
}

\begin{abstract}
Malignant gliomas are the most common type of primary malignant brain tumor that accounts for approximately $20 \%$ of the total brain tumor patients and has no effective treatments (1). There are about 5.2 cases per 100,000 people and every year more than 17,000 new cases are diagnosed in the United States (2). The World Health Organization (WHO) has classified glioma based on their histological patterns into several grades ranging from I to IV (3). Grade I and II glioma are non-malignant, whereas grades III and IV are high-grade glioma and considered malignant (3). The grade III tumors include; anaplastic astrocytoma, anaplastic oligodendroglioma, and anaplastic oligoastrocytoma. The highly malignant grade IV tumors are also known as glioblastoma (GBM), with secondary GBM arising from grade III tumors $(3,4)$. GBM accounts for approximately $82 \%$ of the total malignant glioma cases (2). Malignant gliomas are histologically heterogeneous, comprising various kinds of cells and are highly invasive in nature, with a high degree of mitotic
\end{abstract}

Corresponding Author: Samuel D. Rabkin, Brain Tumor Research Center, Massachusetts General Hospital, 185 Cambridge St., CPZN-3800, Boston, MA 02114, Telephone: 617 726-6817, Fax: 617 643-3422, rabkin@mgh.harvard.edu.

The other authors have no potential conflicts. 
activity, extensive neovascularization and necrotic regions (5). Molecular heterogeneity in glioma includes, but is not limited to: loss or mutation of p53, mutations in the isocitrate dehydrogenase 1 (IDH1) gene, and loss of heterozygosity at chromosome 10q, often occur in lower grade or secondary GBM; abnormalities in growth factor signaling pathways, such as epidermal growth factor receptor (EGFR) amplification/mutation, overexpression of platelet-derived growth factor receptor (PDGFR), deletion/mutation of the phosphatase and tensin homologue on chromosome 10 (PTEN), PIK3CA amplifications/mutations; and abnormalities in the retinoblastoma $(\mathrm{Rb}) / \mathrm{P} 16$ pathway $(4,6,7)$. Because of our expanded molecular understanding of gliomas, the histological classification is likely to be replaced with one that combines histology with molecular characterization (8).

Recently, glioblastoma stem cells (GSCs) have been isolated from malignant glioma specimens, which have the characteristics of self-renewal, differentiation into multiple more mature lineages, and efficient production of tumors in immunodeficient mice that recapitulate the patient's tumor $(9,10)$. GSCs are thought to be responsible for maintenance, progression, and recurrence of glioma. They thus provide representative and relevant models to develop and test therapeutics $(1,9)$. Unfortunately, the development of new therapies for GBM has only recently begun to incorporate GSCs as targets. A number of molecular mechanisms have been identified that mediate the GSC's resistant to therapies, such as activation of DNA damage response pathways, notch, NF- $\kappa$ B, EZH2, and PARP, which suggests that GSCs develops multiple mechanisms of therapeutic resistance that may require combinations of targeted therapies (11-15).

Current conventional therapies include surgical resection, radiation therapy, and temozolomide (TMZ), and in some cases bevacizumab, typically fail to eradicate tumors, resulting in the recurrence of treatment-resistant tumors $(1,5,16)$. Molecular characterization of glioma has led to the development and application of many molecularly targeted therapies in clinical trials for GBM, such as antibodies or small molecules targeting; EGFR, PDGFR, PI3K pathway, cyclin-dependent kinase 4/6, and IDH1 and angiogenesis (VEGF, receptor tyrosine kinases) $(1,17,18)$. Despite advances in molecular understanding and development of molecularly targeted therapies, the clinical benefits remain limited and life expectancy has only been extended from about 12 to approximately 15 months (19). Unique to the brain, the blood brain barrier (BBB) limits the entry of the vast majority of systemically delivered drugs or antibodies to the brain and/or tumor; thereby limiting their therapeutic potential against malignant glioma (1). The histological and molecular heterogeneity both between patients and within tumors remains a great therapeutic challenge. Moreover, glioma-induced immunosuppression and the tumor microenvironment are major confounding factors for immune-mediated therapies (20). Hence, a great need exists for developing novel approaches and improving existing therapeutic strategies that will target the diverse features of malignant glioma, from GSCs to microenvironment.

\section{ONCOLYTIC VIRUS BACKGROUND}

Oncolytic virotherapy is a relatively new therapeutic strategy directed against various cancers including malignant gliomas that is gaining increasing promise (21). Though the concept of using viruses for treating cancer started in the 1950s, it did not progress

Drugs Future. Author manuscript; available in PMC 2016 February 05. 
significantly due to severe toxicities associated with virus infection. The modern era of oncolytic virotherapy started in 1991, when herpes simplex virus (HSV) was engineered for tumor-selective replication by deleting the viral thymidine kinase (TK) gene (22). TKnegative oncolytic HSV (oHSV) was tested in human glioblastoma models, both in vitro and in vivo in mice, but found to be insufficiently attenuated (22). Since then, many OVs have been used in hundreds of preclinical studies in many different cancer models, and a number of clinical trials have been completed or are currently running that have demonstrated safety, as well as provided indications of effective antitumor activity against glioma (21, 23-25). OVs replicate selectively in and kill cancer cells sparing normal cells (21). Once OVs get in cancer cells, they amplify themselves and spread throughout the tumor. This cycle continues until all the cancer cells are eradicated or the host immune system eliminates the OVs (21, 24). Besides direct killing of infected cells, OVs also can kill non-infected cancer cells by various mechanisms, such as induction of specific antitumor immunity and destruction of tumor vasculature $(26,27)$. The mechanisms for tumor selectivity will be discussed for each OV below.

The selectivity of oncolytic virotherapy is achieved by the use of OVs that have a natural preference for cancer cells (such as Newcastle disease virus, parvovirus, reovirus, and retrovirus) or through genetic engineering of viruses (such as adenovirus, measles, herpes simplex virus, myxoma virus, and vesicular stomatitis virus). For safety, vaccine strains of virus are used or viruses are mutated to attenuate pathogenicity. Often genes mutated for cancer selectivity also endow safety $(21,25)$. The brain provides a more dangerous location for viruses than other organs, and thus safety is paramount. OV targeting of cancer cells doesn't usually involve specific genetic alterations, in contrast to molecularly targeted drugs, but rather targets more general features of the transformed phenotype, such as defective antiviral/innate responses, cell cycle controls, and apoptosis induction. Because OVs utilize multiple avenues to destroy tumors (ie,, oncolysis of cancer cells, induction of multiple cell death pathways, in situ amplification and spread, induction of specific antitumor immune responses, destruction of tumor vasculature) they are attractive candidates for the treatment of malignant glioma $(23-25,28)$. In this review, we will focus on those OVs that have been in clinical trials for the treatment of malignant glioma and OVs examined preclinically.

\section{ONCOLYTIC VIRUSES IN CLINICAL TRIAL FOR GLIOMA}

\section{Herpes Simplex Virus}

Preclinical-Herpes simplex virus (HSV) type 1 is an enveloped double stranded DNA virus that is a natural neurotropic pathogen in humans, causing encephalitis (29). The large genome can be manipulated to introduce mutations or deletions in multiple nonessential genes to restrict pathogenicity and virus replication to tumor cells, and provides space for the insertion of transgenes of interest, 'armed' viruses (30). Examples of virus genes that endow tumor selectivity and safety, include: $\gamma 34.5$, the major determinant of HSV-1 neurovirulence and inhibitor of host anti-viral innate responses; ICP6, ribonucleotide reductase, necessary for virus replication in non-dividing cells; Us3, blocks apoptosis and activates Akt; and ICP47, blocks MHC I presentation (30). An advantage of HSV, over most other viruses, is the availability of effective anti-viral drugs to combat unexpected HSV 
replication, providing an additional safety feature (29). OHSVs have been shown to selectively kill human glioma cells and GSCs in vitro and in vivo in a variety of orthotopic glioma models in immunodeficient and syngeneic mice (31). However, oHSV therapy alone may not be sufficient to cure GBM patients (discussed below). Syngeneic mouse glioma models, which are more limited in number, are necessary to study the effects of OV therapy on the immune system, which are an increasingly important component of oncolytic virotherapy. Recently, a mouse GSC line (005 GSC) was developed that forms orthotopic tumors in syngeneic mice that are histologically similar to human GBM (32).

oHSV treatment alone demonstrates significant anti-glioma efficacy in preclinical brain tumor models; however combination therapies are a powerful approach for improving outcomes (31). For example, combining oHSV with current standard-of-care ionizing radiation (33), TMZ $(34,35)$, or anti-angiogenic inhibitors (36), or P13K/Akt pathway inhibitors (37) significantly enhanced anti-glioma efficacy in preclinical glioma models (31, 38). These provide the rationale for translating similar combinations to the clinic. OHSV armed with antiangiogenic transgenes like angiostatin (inhibitor of angiogenesis; G47 $\Delta$ mAngio) or the immunomodulatory IL-12 (G47 - -mIL12) were significantly better than unarmed oHSV, while the combination of the two armed vectors further improved efficacy in vivo (39). In the immunocompetent 005 GSC model, oHSV G47 $\Delta$ was insufficient alone, however, expression of IL12 (G47 - -mIL12) significantly improved efficacy, by at least three distinct mechanisms: direct oncolysis of GSCs, anti-angiogenic effects, and T-cell mediated anti-tumor immune responses (32). Armed oHSVs also include vectors that carry the cytokine Flt3L to evoke a proinflammatory reaction (40) and the apoptosis inducing TRAIL gene (41). Combination of oHSV with topoisomerase inhibitors like etoposide also showed synergy in killing GSCs in vitro (42).

Clinical-Among OVs, oHSV is the furthest along in the clinic. OncoVEX ${ }^{\mathrm{GMCSF}}$ or currently named Talimogene laherparepvec (T-Vec) has completed a pivotal phase III trial, OPTiM, in recurrent melanoma, where it demonstrated a significant improvement in the durable response rate and a longer median survival (43). Its New Drug Application (NDA) received a highly favorable review by the FDA advisory review committee and is awaiting final FDA notice. Four oHSVs (1716, G207, G47 , and M032) are or have been in clinical trials for patients with recurrent malignant gliomas (Table 1) (31). The neurovirulence gene $\gamma 34.5$ is deleted in all of them. In addition, both G207 and G47 $\Delta$ have mutations in the ICP6 gene making viral infection more specific to dividing cancer cells (30). Deletion of the $\gamma 34.5$ gene in these oHSVs $(1716$, G207, and M032) limits or even abolishes their replication in GSCs $(44,45)$. Unfortunately, this was not determined until after clinical trials with 1716 and G207 were initiated and demonstrates the value of GSC models. Deletion of the ICP47 gene in $\mathrm{G} 207$, to create $\mathrm{G} 47 \Delta$, restores replication in GSCs (44), without compromising safety (46). The $\gamma 34.5$-deleted oHSV M032 expresses both human p40 and p35 IL-12 subunits (47).

Although HSV1716 may retain some neurotoxicity (48), 3 clinical trials in recurrent malignant glioma patients have been completed without any evidence of HSV-mediated adverse events or toxicities (49-51). In the first clinical trial, HSV1716 was injected stereotactically into the tumor with doses escalating from $10^{3}-10^{5} \mathrm{pfu}$ in $1 \mathrm{ml}(50)$. Three 
GBM patients survived greater than 14 months after virus injection (50). No virus shedding was detected. In the second trial, 12 patients received $10^{5}$ pfu stereotactically injected into the tumor followed 4-9 days later by tumor resection (51). Infectious virus was recovered from resected tumor in 2 patients, with virus DNA detected in 10 patient tumors (51). As evidence of an immune response, the 2 seronegative patients seroconverted. In the final trial, $10^{5}$ pfu was injected into 8 to 10 sites in the cavity wall after tumor resection (49). Three of 12 patients, 2 newly diagnosed, were clinically stable at 15-22 months following virus injection (49). Here, 2 of 3 seronegative patients seroconverted (49). A phase I trial using HSV1716 is currently running in pediatric patients with surgically removable refractory or recurrent high grade glioma (ClinicalTrials.gov Identifier: NCT02031965) (Table 1).

Phase I/Ib clinical trials using G207 alone or in combination with radiation therapy have been completed in patients with malignant glioma (52-54). In the first, twenty-one patients with recurrent malignant glioma were treated by stereotactic intratumoral injection of G207 (52). This was the first oHSV clinical trial in the US. Four patients survived at least a year after treatment, and there were no reports of HSV-mediated encephalitis or viral shedding in saliva or conjunctival secretions (52). Since G207 was found safe and showed efficacy in the phase I trial, a phase Ib clinical trial was initiated to obtain tissue for analysis (53). Six patients with malignant glioma were enrolled and received two doses of G207 $\left(1.15 \times 10^{9}\right.$ pfu), one intratumorally, followed by multiple injections into the cavity wall after en bloc tumor resection. This allowed for the evaluation of virus replication in the tumor tissue, which was seen at injection sites (53). In a recent Phase 1 trial, G207 was combined with irradiation; stereotactic virus administration followed a day later by focal 5 Gy radiation, which was well tolerated (54). Thus, 36 patients have been safely treated with G207. While there were signs of efficacy, the sample sizes are too small to draw any conclusions about any possible advantages between the 3 different treatment protocols.

G47 $\Delta$ is currently in clinical trials for recurrent glioma in Japan. The sample size for this clinical study (phase I-II) is 21 (WHO JPRN-UMIN000002661). Initial preliminary reports suggest that G47 $\Delta$ is safe and has therapeutic efficacy that is associated with inflammation and can take months to evolve (Todo, T, ASCGT Annual Meeting, 2015). M032 (oHSV expressing human IL-12), was safe after intracerebral injection in HSV-sensitive non-human primates (47), and is in clinical trial for recurrent or progressive GBM (ClinicalTrials.gov Identifier: NCT02062827).

The safety exhibited by oHSVs in patients so far was deemed questionable when the use of oHSV was first proposed, and is testament to our understanding of HSV pathology, the genetic alterations incorporated, and extensive preclinical studies. However, it raises the possibility that less attenuated mutants with enhanced activity, may be sufficiently safe. Combinatorial strategies, be they additional therapeutic transgenes or combinations with other therapies are warranted to improve efficacy.

\section{Adenovirus}

Adenoviruses (Ads) are human DNA viruses with a $36 \mathrm{~kb}$ genome that is amenable to genetic manipulation and hence suitable for gene therapy $(24,28,55)$. The clinical studies performed so far using Ads are based on serotype 5 strains (Ad5). A mutant with a deletion 
of the 55kd E1B gene, called d11520 or ONYX-015, conditionally replicated in p53 mutant cancer cells (55). ONYX-015 was administered into the cavity wall after tumor resection in recurrent malignant glioma patients, with no reported treatment-associated toxicity and maximum tolerated dose (MTD) not reached; however, efficacy was limited (56).

Replication of ONYX-015 and lysis of cancer cells does not entirely depend on the p53 status of the cells, but also on mRNA transport and innate responses, which limits its replication (55). In order to address this issue, another Ad5 mutant, Ad5- $\Delta 24$, was developed to target cells with defects in the p16/Rb pathway (57). Ad5- $\Delta 24$ was engineered by deleting 24 base pairs from the constant region 2 (CR2) of E1A, which prevents E1A binding to Rb for induction of $\mathrm{S}$ phase, and thus replication in normal cells (57). 75\% of glioma patients have defects in the p16/Rb pathway (58). The replication efficiency and specificity of oncolytic Ad can also be improved by using glioma-selective promoters or enhancers (survivin, telomerase reverse transcriptase, VEGFR-1, Ki67, E2F1, glial fibrillary acidic protein, nestin, midkine) to drive expression of early genes or transgenes $(24,59)$.

A more pressing limitation of using Ad5- $\Delta 24$ for the treatment of glioma is that the expression of the Ad5 receptor, coxsackie-adenovirus receptor (CAR), is limited in cancer cells including GBM $(60,61)$. Therefore, Ad5- $\Delta 24$ was further modified by insertion of the RGD-4C peptide sequence into the fiber knob protein to allow infection of cancer cells via integrins ( $\operatorname{vv\beta 3}$ and $\alpha v \beta 5)$ that are specifically expressed on cancer cells (60). The modified virus (Delta-24-RGD-4C) showed significantly enhanced in vitro infectivity of glioma cells and GSCs, and in vivo anti-glioma efficacy in mice (60-62). Other modified adenoviruses, such as Delta-24-EGFR and Ad5.pK7 were generated by insertion of EGFRvIII or a polylysine motif to bind heparin sulfate, respectively, into the fiber knob, which produced highly selective anti-glioma activity $(63,64)$. Adenoviral tropism can also be altered by replacing the Ad5 fiber knob with the Ad3 knob (binds to CD80, CD86, and unknown receptor) (65), or with B-group virus fibers (Ad11, Ad35, or Ad50), which bind to CD46, that is overexpressed in glioma (66), significantly improving efficacy in glioma models.

Two clinical trials (phase I and I/II) using Delta-24-RGD-4C (more recently known as DNX2401) have been completed in patients with recurrent malignant glioma, with results still pending (ClinicalTrials.gov Identifier: NCT00805376 and NCT01582516) (Table 1). To enhance efficacy, two further phase I clinical trials using DNX2401 in combination with IFN- $\gamma$ or TMZ are ongoing in patients with recurrent GBM (NCT01956734, NCT02197169).

\section{Parvovirus}

Parvoviruses are small, non-enveloped, single stranded DNA viruses that belong to the Parvoviridae family (67). They are nonpathogenic in humans, except for human parvovirus B19 (68). Parvoviruses can be divided into two groups: dependoviruses, such as adenoassociated virus (AAV), which requires support from other viruses for its replication; and autonomous parvoviruses, such as $\mathrm{H}-1 \mathrm{PV}$, which replicates independently of other viruses, but dependent upon cellular proliferation $(67,69)$. H-1PV naturally infects rats but is also able to infect and replicate in human cancer cells $(67,69)$. H-1PV is strongly oncolytic even at relatively low multiplicities of infection in several rat and human GBM cell lines (70).

Drugs Future. Author manuscript; available in PMC 2016 February 05. 
Preclinical data showed that $\mathrm{H}-1 \mathrm{PV}$ treatment caused tumor remissions in animal models bearing rat and human gliomas and can also cross the BBB (71). In addition to oncolysis, $\mathrm{H}-1 \mathrm{PV}$-infected tumor cells induce cross-presentation of tumor antigens (72). Based on these efficacy studies and the safety exhibited in clinical trials for other tumors, a phase I/IIa clinical trial was initiated in 2012 in patients with recurrent malignant glioma. ParvOryx01 was administered intratumorally or intravenously followed by tumor resection on day 10 and re-administration into the cavity wall (ClinicalTrials.gov Identifier: NCT01301430) (Table 1) $(67,73)$. This clinical study was recently completed, however, the results are pending.

\section{Reovirus}

Reovirus is a double-stranded RNA virus that is nonpathogenic in humans and has demonstrated oncolytic activity against $\operatorname{GBM}(74,75)$. Serotype 3 reovirus was found to be oncolytic because its replication depended on activated Ras signaling pathways that are often upregulated in cancer cells, including $\operatorname{GBM}(74,76)$. Intratumoral administration of this virus significantly suppressed subcutaneous and intracranial glioma growth, and prolonged survival in immunodeficient (77) and immunocompetent models (78). While intracranial reovirus administration was neurotoxic in severely immunodeficient animals (77), it was nontoxic in immunocompetent rodents and nonhuman primates (78). Recently, all four serotypes of reovirus have been shown to have oncolytic activity in glioma cell lines, as well as in GSCs $(79,80)$.

Two phase I clinical trials using Dearing strain reovirus (Reolysin ${ }^{\circledR}$; pelareorep) have been completed in patients with recurrent malignant glioma. In the first, Reolysin was stereotactically injected intratumorally in 12 patients $\left(10^{7}, 10^{8}\right.$ and $10^{9}$ TCID50 in $\left.0.9 \mathrm{ml}\right)$ (81). Reovirus-specific antibodies were detected in the serum of 10 patients within 4 weeks of virus injection (81). Virus shedding was detected in the saliva of one patient and feces of two patients (81). A number of adverse events occurred, as expected for malignant glioma patients, however 1 grade III event ( $\gamma$-glutamyl transpeptidase elevation) possibly related to treatment occurred, but no MTD was reached. The 3 grade III glioma patients had the best outcomes, and one secondary GBM patient survived 63 weeks (81). In another phase I clinical trial, 15 patients with recurrent malignant glioma were treated with Reolysin in escalating doses from $10^{8}$ to $10^{10} \mathrm{TCID}_{50}, 10$-fold higher than previously, using convectionenhanced delivery (CED) (82). This was the first OV trial using CED in the US. CED is a slow, continuous low-pressure infusion via catheter that provides controlled and better distribution of particles in increased volumes over a larger area (83). Shedding was detected in 2 patients, and one grade III adverse event (convulsions) was possibly related to treatment, but again no MTD was reached. Two of 11 GBM patients survived over 2 yrs (82). There is an ongoing clinical trial in the UK with Reolysin ( $10^{10}$ TCID50) administered by intravenous infusion for malignant gliomas and metastatic brain tumors (ISRCTN 70443973) (Table 1) (84).

\section{Newcastle Disease Virus}

Newcastle disease virus (NDV) is an avian paramyxovirus with single-stranded RNA. It is pathogenic in birds but not in humans (85). Defects in antiviral immunity, often present in GBM, are likely playing a key role in determining tumor-selectivity of NDV (85). Both 
pathogenic (velogenic and mesogenic; MTH68) and nonpathogenic (lentogenic; NDV-HUJ, Hitchner B1) NDV strains have oncolytic activity against GBM (86). NDV vaccine strain V4UPM also showed promising oncolytic activity and induced apoptosis in human malignant glioma both in vitro and in vivo (87). In an orthotopic immunocompetent glioma model, NDV elicited immunogenic cancer cell death, induced strong antitumor immunity (increased infiltration of IFN- $\gamma^{+}$T cells and reduced accumulation of myeloid derived suppressor cells in tumor), and tumor-specific immunological memory (88). Intravenous delivery of NDV (1 mesogenic and 2 lentogenic) was found safe in non-human primates, but no virus RNA was detected in the brain (89). In a two part phase I/II clinical trial of NDVHUJ, NDV was administered intravenously in a dose escalation scheme in 6 patients, with one-cycle dosing steps beginning at 0.1 billion infectious units (BIU; $1 \mathrm{BIU}=1 \times 10^{9} \mathrm{EID}_{50}$ (50\% egg infectious dose)) up to 55 BIU followed by maintenance at 11 BIU until radiologic progression, due to limited virus and cost of production (90). In the second part, 5 patients received $11 \mathrm{BIU}$. Low-grade fever was observed in 5 patients, anti-NDV hemagglutinin antibodies were found in all patients within 5-29 days of treatment, and infectious NDV-HUJ was recovered from one tumor (90). One patient showed a nondurable complete response to NDV-HUJ therapy and 2 GBM patients in the second part survived over 60 weeks (90).

\section{Measles Virus}

Measles virus (MV) is a negative-strand RNA paramyxovirus that is neurotropic and in rare circumstances causes encephalitis in human (91). The attenuated Edmonston vaccine strain, used as oncolytic MV, efficiently replicates in glioma cells and GSCs producing strong cytopathic and oncolytic effects $(92,93)$. It mainly uses CD46 as a receptor, which is often highly expressed on glioma cells, rather than SLAM (signaling lymphocyte activation molecule) to enter to its target cells (92). The Edmonston strain has two glycoproteins, hemagglutinin $(\mathrm{H})$ and fusion $(\mathrm{F})$, which are crucial for its tumor selectivity and oncolytic activity. Mutations, such as insertions of a single chain antibody against glioma-associated EGFRvIII (94), or IL-13, as a ligand to glioma-specific receptor IL-13Ra2 (95), in the H protein of Edmonston strain altered its affinity from CD46/SLAM to EGFRvIII or IL-13Ra2 expressing glioma cells. The F protein is responsible for membrane fusion and syncytia formation, which eventually lead to apoptosis of the infected cells (92). MV was engineered to express a soluble carcinoembryonic antigen (MV-CEA), where CEA can be used as a serum marker of MV's replication $(92,96)$. MV-CEA can effectively reduce the subcutaneous and intracranial glioma growth in vivo in nude mice (96). Intracerebral administration of MV-CEA in rhesus macaques was found to be safe, providing support for clinical trials in patients with recurrent malignant gliomas (97). A phase I clinical trial using oncolytic MV-CEA is currently ongoing in MV-immune patients with recurrent GBM at the Mayo Clinic (ClinicalTrials.gov Identifier: NCT00390299) (Table 1) (92).

\section{Poliovirus}

Poliovirus (PV) is a neurotropic non-enveloped positive-strand human RNA virus. It is very neuropathogenic and uses the CD155 receptor, which is highly expressed on cells of neuronal origin, including malignant gliomas (98). Neuropathogenicity can be abolished by replacing the internal ribosomal entry site (IRES) of PV with the IRES of non-neurotoxic 
human rhinovirus type 2 (99). This recombinant PV, called PVS-RIPO, has poor growth in neural cell lines and is not virulent in CD155 transgenic mice (99). Though PVS-RIPO does not efficiently propagate in neuronal tissue, it is highly proliferative and strongly oncolytic in glioma cell lines and primary glioma tissues (100). PVS-RIPO was also efficacious in inhibiting intracranial or subcutaneous glioma growth in vivo (100). PVS-RIPO propagation in glioma cells can be enhanced through activation of Mnk1 and stimulation of capindependent translation (98). Intrathecal delivery of PVS-RIPO was safe in rats and prolonged survival in a model of multifocal or leptomeningeal glioblastoma (101). After extensive safety testing in PV-sensitive nonhuman primates after intrathecal injection (102), PVS-RIPO recently entered a phase I clinical trial for patients with recurrent malignant gliomas at the Duke University Medical Center (ClinicalTrials.gov Identifier:

NCT01491893) (Table 1).

\section{Retroviruses}

Retroviruses are enveloped animal viruses with a positive-strand RNA genome. Reverse transcription of retroviral RNA into DNA, followed by DNA integration into the host genome are the hallmarks of retroviral replication (103). Non-lytic replicating $\gamma$-retroviruses (retroviral replicating vectors, RRVs) have been engineered from murine leukemia viruses (MLVs) (104). RRVs effectively transduced malignant glioma cells, suppressed tumor growth after addition of prodrug, and extended survival in intracranial glioma models without producing any treatment related toxicity $(105,106)$. An amphotropic RRV vector, Toca 511 (vocimagene amiretrorepvec), encoding an optimized cytosine deaminase (CD) gene was constructed (107). CD catalyzes the conversion of the antifungal prodrug 5fluorocytosine (5-FC) to the cytotoxic drug 5-fluorouracil (5-FU). Toca 511 demonstrated significant antiglioma activity both in vitro and in vivo, especially after 5-FC administration (108). In a preclinical TMZ-sensitive glioma model, the combination of TMZ, 5-FC and Toca 511 was more efficacious than either treatment alone and no significant hematologic effects were observed (109). When Toca 511 was administered intravenously, it infected and spread in intracranial gliomas in mice (110). Interestingly, it was only effective after intravenous delivery in immunocompetent mice and similar to intratumoral injection with 5FC, whereas in immunodeficient mice, intravenous delivery was even less effective than intratumoral injection without 5-FC (110).

Toca 511, in combination with an orally administered 5-FC, is currently in 3 clinical trials for recurrent malignant gliomas. In the first phase 1 trial clinical trial, Toca 511 was injected intratumorally, and 3-4 weeks later 5-FC was administered (6-day cycle every month) for a maximum of 6 times (NCT01156584) (Table 1). This was followed by another doseescalation clinical trial (NCT01470794), where Toca 511 was injected into the tumor resection cavity wall followed by three repeats of oral 5-FC (8-day cycle every 2 months) starting 7 weeks after Toca 511 injection (Table 1). Finally, a dose escalating trial with intravenous delivery, followed by tumor resection at day 11 and an additional Toca 511 injection into the cavity wall is ongoing (NCT01985256).

Drugs Future. Author manuscript; available in PMC 2016 February 05. 


\section{PRECLINICAL STUDIES OF OTHER ONCOLYTIC VIRUSES TARGETING GLIOMA}

\section{Vesicular stomatitis virus}

Vesicular stomatitis virus (VSV) is a negative-strand RNA virus of the Rhabdoviridae family, which has a rapid life cycle and releases progeny virus from infected cells within hours of infection $(28,111)$. VSV is not known to cause any significant disease in human but it is neurotoxic to mice following infection with high doses (111). VSV is highly sensitive to type I interferon (IFN) responses, therefore, administration of exogenous IFN at the time of VSV infection abolishes VSV-mediated toxicity in mice (111). Due to its high IFN-sensitivity, VSV selectively replicates in cells with defective IFN responses, which is often the case with cancer cells (111). VSV ${ }^{\Delta M 51}$, a mutant VSV with a methionine deletion at position 51 of the VSV M-protein, cannot block anti-viral IFN responses but efficiently replicates in glioma cells (112). Systemic delivery of VSV ${ }^{\Delta \mathrm{M} 51}$ effectively reduced subcutaneous and intracranial human U87 glioma growth (113). There are a number strategies being developed to increase tumor selectivity and safety, such as replacement of the neurotoxic VSV glycoprotein with those from other viruses $(114,115)$, or attenuating the virus by adding sequences or genes (ie., IFN $\beta$ ) $(116,117)$. VSV-IFN-beta is currently in clinical trial for hepatocellular carcinoma (NCT01628640). Selection of glioma selective OV does not always produce safe viruses. VSV-rp30 (with single mutations in the P and L genes) was isolated through serial passaging in glioma cells, and replicated more rapidly and effectively than wild-type VSV (118). Unfortunately it was cytotoxic to normal human glial cells (118).

\section{Myxoma}

Myxoma virus (MYXV) is an enveloped double stranded DNA virus belonging to the Poxviridae family (119). MYXV is highly species specific and its pathogenicity is completely restricted to European rabbits (119). However, MYXV can infect various human cancer cells mainly because they fail to induce synergistic interferon and tumor necrosis factor antiviral responses that efficiently abort MYXV replication in normal primary human cells (120). Tumor cells also have constitutively active cellular transformation pathways like Akt that support myxoma's permissiveness (121). Several preclinical in vivo modeling studies using glioma cell lines, GSCs, and primary human glioma cells have demonstrated that MYXV is potentially safe as an oncolytic virus and efficacious against glioma (122124). Hence, MYXV is currently being developed as a potential therapeutic for malignant gliomas.

\section{STRATEGIES TO IMPROVE EFFICACY AND FUTURE DIRECTIONS}

Oncolytic viral therapy has been safe for human patients so far and current efforts are directed towards improving upon existing methodologies to enhance tumor killing. Engineering newer generations of recombinant, yet nonpathogenic OVs is important to improve the therapeutic efficacy of existing viruses by enhancing virus replication and spread, and infectivity specific to tumor cells. The strategies include building on those examples already described, such as; selection of more selective and oncolytic virus mutants

Drugs Future. Author manuscript; available in PMC 2016 February 05. 
$(45,118)$, screening for agents that synergize with OV in killing glioma cells $(38,125)$, and expression of therapeutic transgenes (126). Improvements in therapeutic efficacy depend upon a better understanding and manipulation of the tumor microenvironment and oncolysis, with special attention to host immune responses. Combining OVs with systemic immune checkpoint blockers $(127,128)$ or expressing antibodies to them $(129,130)$ has the potential to increase the host's immune responses towards the tumor, even in the brain (131).

Most of the OVs described were administered directly into the tumor or the resection cavity wall, which obviates barriers to delivery such as the BBB, neutralizing antibodies and inactivating serum factors, and antiviral immune responses. However, intratumoral delivery of OVs for glioma involves a surgical procedure and multiple injections entail increasing risk. To improve distribution, CED has been used $(25,83)$, but a better analysis of actual virus spread after CED is necessary to determine its benefit (132). OV-infected carrier cells can be used to deliver OV to malignant gliomas $(133,134)$. Potential advantages of this approach are that carrier cells escape antiviral immunity, a major factor that limits virus distribution, and traffic to the tumor site from the periphery. In several preclinical studies, human mesenchymal stem cells (hMSCs) and neural stem cells (hNSCs) were effectively used as carriers to deliver oAd and oHSV to human gliomas (135-137). After intravascular administration of hMSCs carrying Ad- $\Delta 24-$ RGD (hMSCs- $\Delta 24$ ) into the carotid artery of mice, virus localized into glioma xenografts, infected glioma cells, and increased survival (137). Intratumoral administration of hMSCs-carrying oHSV-mCh (hMSCs-oHSV-mCh) significantly reduced glioma growth compared to control (oHSV-mCh alone) treatment (136). As hNSCs are currently in clinical trial for glioma (NCT01172964), these preclinical studies provide a basis to use stem cells as OV carrier for malignant glioma in patients. Another strategy to overcome host antiviral immune responses is to induce temporary immunosuppression using metronomic cyclophosphamide (25). This strategy enhanced therapeutic efficacy of oHSV in a rat glioma model (138). Cyclophosphamide treatment has been used with OV in several clinical trials for other solid tumors (NCT00450814, NCT01598129) $(25,139)$.

The application of OV for the treatment of malignant glioma is accelerating, with a diversity of viruses entering clinical trials. As we gain more understanding about the way these OV behave in patients, whether they replicate and/or spread effectively, the type of inflammatory responses induced, their effects on tumor progression and tumor immunity, and clinical outcomes, we will be able to develop more effective OVs and strategies to combine them with agents that will minimize detrimental responses and maximize beneficial effects. These early clinical trials have been marked by a remarkable degree of safety and minimal adverse events, coupled to anecdotal examples of impressive antitumor efficacy. With the dire outcome for malignant glioma patients, OV are one of the most promising therapeutic strategies on the horizon.

\section{Acknowledgments}

The authors thank past and current members of the laboratory for contributing to our research, which has been supported by grants from the National Cancer Institute, National Institutes of Neurological Disorders and Stroke, and the Thomas A. Pappas Chair in Neurosciences (to SD Rabkin).

Drugs Future. Author manuscript; available in PMC 2016 February 05. 
SDR is a co-inventor on patents filed by Georgetown University and Massachusetts General Hospital relating to oncolytic herpes simplex viruses.

\section{REFERENCES}

1. Carlsson SK, Brothers SP, Wahlestedt C. Emerging treatment strategies for glioblastoma multiforme. EMBO molecular medicine. 2014; 6(11):1359-1370. [PubMed: 25312641]

2. Ostrom QT, Gittleman H, Liao P, et al. CBTRUS statistical report: primary brain and central nervous system tumors diagnosed in the United States in 2007-2011. Neuro-oncology. 2014; 16(Suppl 4):iv1-iv63. [PubMed: 25304271]

3. Louis DN, Ohgaki H, Wiestler OD, et al. The 2007 WHO classification of tumours of the central nervous system. Acta neuropathologica. 2007; 114(2):97-109. [PubMed: 17618441]

4. Ohgaki H, Kleihues P. Genetic pathways to primary and secondary glioblastoma. Am J Pathol. 2007; 170(5):1445-1453. [PubMed: 17456751]

5. Wen PY, Kesari S. Malignant gliomas in adults. N Engl J Med. 2008; 359(5):492-507. [PubMed: 18669428]

6. Parsons DW, Jones S, Zhang X, et al. An integrated genomic analysis of human glioblastoma multiforme. Science. 2008; 321(5897):1807-1812. [PubMed: 18772396]

7. Sturm D, Bender S, Jones DT, et al. Paediatric and adult glioblastoma: multiform (epi)genomic culprits emerge. Nature reviews Cancer. 2014; 14(2):92-107. [PubMed: 24457416]

8. Louis DN, Perry A, Burger P, et al. International Society Of Neuropathology--Haarlem consensus guidelines for nervous system tumor classification and grading. Brain Pathol. 2014; 24(5):429-435. [PubMed: 24990071]

9. Dirks PB. Brain tumor stem cells: the cancer stem cell hypothesis writ large. Molecular oncology. 2010; 4(5):420-430. [PubMed: 20801091]

10. Lathia JD, Mack SC, Mulkearns-Hubert EE, Valentim CL, Rich JN. Cancer stem cells in glioblastoma. Genes \& development. 2015; 29(12):1203-1217. [PubMed: 26109046]

11. Bao S, Wu Q, McLendon RE, et al. Glioma stem cells promote radioresistance by preferential activation of the DNA damage response. Nature. 2006; 444(7120):756-760. [PubMed: 17051156]

12. Wang J, Wakeman TP, Lathia JD, et al. Notch promotes radioresistance of glioma stem cells. Stem cells. 2010; 28(1):17-28. [PubMed: 19921751]

13. Bhat KP, Balasubramaniyan V, Vaillant B, et al. Mesenchymal differentiation mediated by NFkappaB promotes radiation resistance in glioblastoma. Cancer cell. 2013; 24(3):331-346. [PubMed: 23993863]

14. Venere M, Hamerlik P, Wu Q, et al. Therapeutic targeting of constitutive PARP activation compromises stem cell phenotype and survival of glioblastoma-initiating cells. Cell death and differentiation. 2014; 21(2):258-269. [PubMed: 24121277]

15. Kim SH, Joshi K, Ezhilarasan R, et al. EZH2 protects glioma stem cells from radiation-induced cell death in a MELK/FOXM1-dependent manner. Stem cell reports. 2015; 4(2):226-238. [PubMed: 25601206]

16. Cho DY, Lin SZ, Yang WK, et al. Targeting cancer stem cells for treatment of glioblastoma multiforme. Cell transplantation. 2013; 22(4):731-739. [PubMed: 23594862]

17. Tanaka S, Louis DN, Curry WT, Batchelor TT, Dietrich J. Diagnostic and therapeutic avenues for glioblastoma: no longer a dead end? Nat Rev Clin Oncol. 2013; 10(1):14-26. [PubMed: 23183634]

18. Prados MD, Byron SA, Tran NL, et al. Toward precision medicine in glioblastoma: the promise and the challenges. Neuro-oncology. 2015; 17(8):1051-1063. [PubMed: 25934816]

19. Preusser M, de Ribaupierre S, Wohrer A, Erridge SC, Hegi M, Weller M, Stupp R. Current concepts and management of glioblastoma. Ann Neurol. 2011; 70(1):9-21. [PubMed: 21786296]

20. Perng P, Lim M. Immunosuppressive Mechanisms of Malignant Gliomas: Parallels at Non-CNS Sites. Frontiers in oncology. 2015; 5:153. [PubMed: 26217588]

21. Russell SJ, Peng KW, Bell JC. Oncolytic virotherapy. Nat Biotechnol. 2012; 30(7):658-670. [PubMed: 22781695]

Drugs Future. Author manuscript; available in PMC 2016 February 05. 
22. Martuza RL, Malick A, Markert JM, Ruffner KL, Coen DM. Experimental therapy of human glioma by means of a genetically engineered virus mutant. Science. 1991; 252(5007):854-856. [PubMed: 1851332]

23. Auffinger B, Ahmed AU, Lesniak MS. Oncolytic virotherapy for malignant glioma: translating laboratory insights into clinical practice. Frontiers in oncology. 2013; 3:32. [PubMed: 23443138]

24. Murphy AM, Rabkin SD. Current status of gene therapy for brain tumors. Translational research : the journal of laboratory and clinical medicine. 2013; 161(4):339-354. [PubMed: 23246627]

25. Kaufmann JK, Chiocca EA. Glioma virus therapies between bench and bedside. Neuro-oncology. 2014; 16(3):334-351. [PubMed: 24470549]

26. Angarita FA, Acuna SA, Ottolino-Perry K, Zerhouni S, McCart JA. Mounting a strategic offense: fighting tumor vasculature with oncolytic viruses. Trends Mol Med. 2013; 19(6):378-392. [PubMed: 23540715]

27. Chiocca EA, Rabkin SD. Oncolytic viruses and their application to cancer immunotherapy. Cancer Immunol Res. 2014; 2(4):295-300. [PubMed: 24764576]

28. Wollmann G, Ozduman K, van den Pol AN. Oncolytic virus therapy for glioblastoma multiforme: concepts and candidates. Cancer journal. 2012; 18(1):69-81.

29. Whitley RJ. Herpes simplex encephalitis: adolescents and adults. Antiviral research. 2006; 71(23):141-148. [PubMed: 16675036]

30. Peters C, Rabkin SD. Designing herpes viruses as oncolytics. Molecular Therapy - Oncolytics. 2015; 2:15010. [PubMed: 26462293]

31. Ning J, Wakimoto H. Oncolytic herpes simplex virus-based strategies: toward a breakthrough in glioblastoma therapy. Frontiers in microbiology. 2014; 5:303. [PubMed: 24999342]

32. Cheema TA, Wakimoto H, Fecci PE, et al. Multifaceted oncolytic virus therapy for glioblastoma in an immunocompetent cancer stem cell model. Proceedings of the National Academy of Sciences of the United States of America. 2013; 110(29):12006-12011. [PubMed: 23754388]

33. Advani SJ, Markert JM, Sood RF, et al. Increased oncolytic efficacy for high-grade gliomas by optimal integration of ionizing radiation into the replicative cycle of HSV-1. Gene therapy. 2011; 18(11):1098-1102. [PubMed: 21544094]

34. Aghi M, Rabkin S, Martuza RL. Effect of chemotherapy-induced DNA repair on oncolytic herpes simplex viral replication. Journal of the National Cancer Institute. 2006; 98(1):38-50. [PubMed: 16391370]

35. Kanai R, Rabkin SD, Yip S, et al. Oncolytic virus-mediated manipulation of DNA damage responses: synergy with chemotherapy in killing glioblastoma stem cells. Journal of the National Cancer Institute. 2012; 104(1):42-55. [PubMed: 22173583]

36. Zhang W, Fulci G, Buhrman JS, et al. Bevacizumab with angiostatin-armed oHSV increases antiangiogenesis and decreases bevacizumab-induced invasion in U87 glioma. Molecular therapy : the journal of the American Society of Gene Therapy. 2012; 20(1):37-45. [PubMed: 21915104]

37. Kanai R, Wakimoto H, Martuza RL, Rabkin SD. A novel oncolytic herpes simplex virus that synergizes with phosphoinositide 3-kinase/Akt pathway inhibitors to target glioblastoma stem cells. Clinical cancer research : an official journal of the American Association for Cancer Research. 2011; 17(11):3686-3696. [PubMed: 21505062]

38. Kanai R, Rabkin SD. Combinatorial strategies for oncolytic herpes simplex virus therapy of brain tumors. CNS oncology. 2013; 2(2):129-142. [PubMed: 23687568]

39. Zhang W, Fulci G, Wakimoto H, et al. Combination of oncolytic herpes simplex viruses armed with angiostatin and IL-12 enhances antitumor efficacy in human glioblastoma models. Neoplasia. 2013; 15(6):591-599. [PubMed: 23730207]

40. Barnard Z, Wakimoto H, Zaupa C, et al. Expression of FMS-like tyrosine kinase 3 ligand by oncolytic herpes simplex virus type I prolongs survival in mice bearing established syngeneic intracranial malignant glioma. Neurosurgery. 2012; 71(3):741-748. discussion 8. [PubMed: 22653387]

41. Tamura K, Wakimoto H, Agarwal AS, et al. Multimechanistic tumor targeted oncolytic virus overcomes resistance in brain tumors. Molecular therapy : the journal of the American Society of Gene Therapy. 2013; 21(1):68-77. [PubMed: 22929661]

Drugs Future. Author manuscript; available in PMC 2016 February 05. 
42. Cheema TA, Kanai R, Kim GW, Wakimoto H, Passer B, Rabkin SD, Martuza RL. Enhanced antitumor efficacy of low-dose Etoposide with oncolytic herpes simplex virus in human glioblastoma stem cell xenografts. Clinical cancer research : an official journal of the American Association for Cancer Research. 2011; 17(23):7383-7393. [PubMed: 21976549]

43. Andtbacka RH, Kaufman HL, Collichio F, et al. Talimogene Laherparepvec Improves Durable Response Rate in Patients With Advanced Melanoma. J Clin Oncol. 2015

44. Wakimoto H, Kesari S, Farrell CJ, et al. Human glioblastoma-derived cancer stem cells: establishment of invasive glioma models and treatment with oncolytic herpes simplex virus vectors. Cancer research. 2009; 69(8):3472-3481. [PubMed: 19351838]

45. Kanai R, Zaupa C, Sgubin D, Antoszczyk SJ, Martuza RL, Wakimoto H, Rabkin SD. Effect of gamma34.5 deletions on oncolytic herpes simplex virus activity in brain tumors. Journal of virology. 2012; 86(8):4420-4431. [PubMed: 22345479]

46. Todo T, Martuza RL, Rabkin SD, Johnson PA. Oncolytic herpes simplex virus vector with enhanced MHC class I presentation and tumor cell killing. Proceedings of the National Academy of Sciences of the United States of America. 2001; 98(11):6396-6401. [PubMed: 11353831]

47. Roth JC, Cassady KA, Cody JJ, et al. Evaluation of the safety and biodistribution of M032, an attenuated herpes simplex virus type 1 expressing hIL-12, after intracerebral administration to aotus nonhuman primates. Human gene therapy Clinical development. 2014; 25(1):16-27. [PubMed: 24649838]

48. Lasner TM, Tal-Singer R, Kesari S, Lee VM, Trojanowski JQ, Fraser NW. Toxicity and neuronal infection of a HSV-1 ICP34.5 mutant in nude mice. J Neurovirol. 1998; 4(1):100-105. [PubMed: 9531017]

49. Harrow S, Papanastassiou V, Harland J, et al. HSV1716 injection into the brain adjacent to tumour following surgical resection of high-grade glioma: safety data and long-term survival. Gene therapy. 2004; 11(22):1648-1658. [PubMed: 15334111]

50. Rampling R, Cruickshank G, Papanastassiou V, et al. Toxicity evaluation of replication-competent herpes simplex virus (ICP 34.5 null mutant 1716) in patients with recurrent malignant glioma. Gene therapy. 2000; 7(10):859-866. [PubMed: 10845724]

51. Papanastassiou V, Rampling R, Fraser M, et al. The potential for efficacy of the modified (ICP 34.5(-)) herpes simplex virus HSV1716 following intratumoural injection into human malignant glioma: a proof of principle study. Gene therapy. 2002; 9(6):398-406. [PubMed: 11960316]

52. Markert JM, Medlock MD, Rabkin SD, et al. Conditionally replicating herpes simplex virus mutant, G207 for the treatment of malignant glioma: results of a phase I trial. Gene therapy. 2000; 7(10):867-874. [PubMed: 10845725]

53. Markert JM, Liechty PG, Wang W, et al. Phase Ib trial of mutant herpes simplex virus G207 inoculated pre-and post-tumor resection for recurrent GBM. Molecular therapy : the journal of the American Society of Gene Therapy. 2009; 17(1):199-207. [PubMed: 18957964]

54. Markert JM, Razdan SN, Kuo HC, et al. A phase 1 trial of oncolytic HSV-1, G207, given in combination with radiation for recurrent GBM demonstrates safety and radiographic responses. Molecular therapy : the journal of the American Society of Gene Therapy. 2014; 22(5):10481055. [PubMed: 24572293]

55. Jiang H, Gomez-Manzano C, Rivera-Molina Y, Lang FF, Conrad CA, Fueyo J. Oncolytic adenovirus research evolution: from cell-cycle checkpoints to immune checkpoints. Current opinion in virology. 2015; 13:33-39. [PubMed: 25863716]

56. Chiocca EA, Abbed KM, Tatter S, et al. A phase I open-label, dose-escalation, multi-institutional trial of injection with an E1B-Attenuated adenovirus, ONYX-015, into the peritumoral region of recurrent malignant gliomas, in the adjuvant setting. Molecular therapy : the journal of the American Society of Gene Therapy. 2004; 10(5):958-966. [PubMed: 15509513]

57. Fueyo J, Gomez-Manzano C, Alemany R, et al. A mutant oncolytic adenovirus targeting the Rb pathway produces anti-glioma effect in vivo. Oncogene. 2000; 19(1):2-12. [PubMed: 10644974]

58. Cancer Genome Atlas Research Network. Comprehensive genomic characterization defines human glioblastoma genes and core pathways. Nature. 2008; 455(7216):1061-1068. [PubMed: 18772890]

59. Alonso MM, Cascallo M, Gomez-Manzano C, et al. ICOVIR-5 shows E2F1 addiction and potent antiglioma effect in vivo. Cancer research. 2007; 67(17):8255-8263. [PubMed: 17804740]

Drugs Future. Author manuscript; available in PMC 2016 February 05. 
60. Fueyo J, Alemany R, Gomez-Manzano C, et al. Preclinical characterization of the antiglioma activity of a tropism-enhanced adenovirus targeted to the retinoblastoma pathway. Journal of the National Cancer Institute. 2003; 95(9):652-660. [PubMed: 12734316]

61. Jiang H, Clise-Dwyer K, Ruisaard KE, et al. Delta-24-RGD oncolytic adenovirus elicits antiglioma immunity in an immunocompetent mouse model. PloS one. 2014; 9(5):e97407. [PubMed: 24827739]

62. Jiang H, Gomez-Manzano C, Aoki H, et al. Examination of the therapeutic potential of Delta-24RGD in brain tumor stem cells: role of autophagic cell death. J Natl Cancer Inst. 2007; 99(18): 1410-1414. [PubMed: 17848677]

63. Piao Y, Jiang H, Alemany R, et al. Oncolytic adenovirus retargeted to Delta-EGFR induces selective antiglioma activity. Cancer gene therapy. 2009; 16(3):256-265. [PubMed: 18927600]

64. Ulasov IV, Zhu ZB, Tyler MA, et al. Survivin-driven and fiber-modified oncolytic adenovirus exhibits potent antitumor activity in established intracranial glioma. Human gene therapy. 2007; 18(7):589-602. [PubMed: 17630837]

65. Nandi S, Ulasov IV, Rolle CE, Han Y, Lesniak MS. A chimeric adenovirus with an Ad 3 fiber knob modification augments glioma virotherapy. The journal of gene medicine. 2009; 11(11): 1005-1011. [PubMed: 19688792]

66. Brouwer E, Havenga MJ, Ophorst O, et al. Human adenovirus type 35 vector for gene therapy of brain cancer: improved transduction and bypass of pre-existing anti-vector immunity in cancer patients. Cancer Gene Ther. 2007; 14(2):211-219. [PubMed: 17082793]

67. Angelova AL, Geletneky K, Nuesch JP, Rommelaere J. Tumor Selectivity of Oncolytic Parvoviruses: From in vitro and Animal Models to Cancer Patients. Front Bioeng Biotechnol. 2015; 3:55. [PubMed: 25954743]

68. Luo Y, Qiu J. Human parvovirus B19: a mechanistic overview of infection and DNA replication. Future virology. 2015; 10(2):155-167. [PubMed: 26097496]

69. Rommelaere J, Geletneky K, Angelova AL, et al. Oncolytic parvoviruses as cancer therapeutics. Cytokine \& growth factor reviews. 2010; 21(2-3):185-195. [PubMed: 20211577]

70. Herrero YCM, Cornelis JJ, Herold-Mende C, Rommelaere J, Schlehofer JR, Geletneky K. Parvovirus H-1 infection of human glioma cells leads to complete viral replication and efficient cell killing. International journal of cancer Journal international du cancer. 2004; 109(1):76-84. [PubMed: 14735471]

71. Geletneky K, Kiprianova I, Ayache A, et al. Regression of advanced rat and human gliomas by local or systemic treatment with oncolytic parvovirus H-1 in rat models. Neuro-oncology. 2010; 12(8):804-814. [PubMed: 20299703]

72. Moehler MH, Zeidler M, Wilsberg V, et al. Parvovirus H-1-induced tumor cell death enhances human immune response in vitro via increased phagocytosis, maturation, and cross-presentation by dendritic cells. Human gene therapy. 2005; 16(8):996-1005. [PubMed: 16076257]

73. Geletneky K, Huesing J, Rommelaere J, et al. Phase I/IIa study of intratumoral/intracerebral or intravenous/intracerebral administration of Parvovirus H-1 (ParvOryx) in patients with progressive primary or recurrent glioblastoma multiforme: ParvOryx01 protocol. BMC cancer. 2012; 12:99. [PubMed: 22436661]

74. Maitra R, Ghalib MH, Goel S. Reovirus: a targeted therapeutic--progress and potential. Mol Cancer Res. 2012; 10(12):1514-1525. [PubMed: 23038811]

75. Thirukkumaran C, Morris DG. Oncolytic Viral Therapy Using Reovirus. Methods Mol Biol. 2015; 1317:187-223. [PubMed: 26072409]

76. Coffey MC, Strong JE, Forsyth PA, Lee PW. Reovirus therapy of tumors with activated Ras pathway. Science. 1998; 282(5392):1332-1334. [PubMed: 9812900]

77. Wilcox ME, Yang W, Senger D, et al. Reovirus as an oncolytic agent against experimental human malignant gliomas. Journal of the National Cancer Institute. 2001; 93(12):903-912. [PubMed: 11416111]

78. Yang WQ, Lun X, Palmer CA, et al. Efficacy and safety evaluation of human reovirus type 3 in immunocompetent animals: racine and nonhuman primates. Clinical cancer research : an official journal of the American Association for Cancer Research. 2004; 10(24):8561-8576. [PubMed: 15623640]

Drugs Future. Author manuscript; available in PMC 2016 February 05. 
79. Alloussi SH, Alkassar M, Urbschat S, Graf N, Gartner B. All reovirus subtypes show oncolytic potential in primary cells of human high-grade glioma. Oncology reports. 2011; 26(3):645-649. [PubMed: 21637921]

80. van den Hengel SK, Balvers RK, Dautzenberg IJ, et al. Heterogeneous reovirus susceptibility in human glioblastoma stem-like cell cultures. Cancer gene therapy. 2013; 20(9):507-513. [PubMed: 23907517]

81. Forsyth P, Roldan G, George D, et al. A phase I trial of intratumoral administration of reovirus in patients with histologically confirmed recurrent malignant gliomas. Molecular therapy : the journal of the American Society of Gene Therapy. 2008; 16(3):627-632. [PubMed: 18253152]

82. Kicielinski KP, Chiocca EA, Yu JS, Gill GM, Coffey M, Markert JM. Phase 1 clinical trial of intratumoral reovirus infusion for the treatment of recurrent malignant gliomas in adults. Molecular therapy : the journal of the American Society of Gene Therapy. 2014; 22(5):10561062. [PubMed: 24553100]

83. Nakamura T, Saito R, Sugiyama S, Sonoda Y, Kumabe T, Tominaga T. Local convectionenhanced delivery of chemotherapeutic agent transiently opens blood-brain barrier and improves efficacy of systemic chemotherapy in intracranial xenograft tumor model. Cancer letters. 2011; 310(1):77-83. [PubMed: 21763069]

84. Chakrabarty R, Tran H, Selvaggi G, Hagerman A, Thompson B, Coffey M. The oncolytic virus, pelareorep, as a novel anticancer agent: a review. Investigational new drugs. 2015; 33(3):761-774. [PubMed: 25693885]

85. Fournier P, Schirrmacher V. Oncolytic Newcastle Disease Virus as Cutting Edge between Tumor and Host. Biology (Basel). 2013; 2(3):936-975. [PubMed: 24833054]

86. Lam HY, Yeap SK, Rasoli M, Omar AR, Yusoff K, Suraini AA, Alitheen NB. Safety and clinical usage of newcastle disease virus in cancer therapy. Journal of biomedicine \& biotechnology. 2011; 2011:718710. [PubMed: 22131816]

87. Zulkifli MM, Ibrahim R, Ali AM, et al. Newcastle diseases virus strain V4UPM displayed oncolytic ability against experimental human malignant glioma. Neurological research. 2009; 31(1):3-10. [PubMed: 18937888]

88. Koks CA, Garg AD, Ehrhardt M, et al. Newcastle disease virotherapy induces long-term survival and tumor-specific immune memory in orthotopic glioma through the induction of immunogenic cell death. International journal of cancer Journal international du cancer. 2015; 136(5):E313E325. [PubMed: 25208916]

89. Buijs PR, van Amerongen G, van Nieuwkoop S, et al. Intravenously injected Newcastle disease virus in non-human primates is safe to use for oncolytic virotherapy. Cancer gene therapy. 2014; 21(11):463-471. [PubMed: 25257305]

90. Freeman AI, Zakay-Rones Z, Gomori JM, et al. Phase I/II trial of intravenous NDV-HUJ oncolytic virus in recurrent glioblastoma multiforme. Molecular therapy : the journal of the American Society of Gene Therapy. 2006; 13(1):221-228. [PubMed: 16257582]

91. Reuter D, Schneider-Schaulies J. Measles virus infection of the CNS: human disease, animal models, and approaches to therapy. Medical microbiology and immunology. 2010; 199(3):261271. [PubMed: 20390298]

92. Msaouel P, Opyrchal M, Domingo Musibay E, Galanis E. Oncolytic measles virus strains as novel anticancer agents. Expert opinion on biological therapy. 2013; 13(4):483-502. [PubMed: 23289598]

93. Allen C, Opyrchal M, Aderca I, et al. Oncolytic measles virus strains have significant antitumor activity against glioma stem cells. Gene therapy. 2013; 20(4):444-449. [PubMed: 22914495]

94. Allen C, Vongpunsawad S, Nakamura T, et al. Retargeted oncolytic measles strains entering via the EGFRvIII receptor maintain significant antitumor activity against gliomas with increased tumor specificity. Cancer research. 2006; 66(24):11840-11850. [PubMed: 17178881]

95. Allen C, Paraskevakou G, Iankov I, et al. Interleukin-13 displaying retargeted oncolytic measles virus strains have significant activity against gliomas with improved specificity. Molecular therapy : the journal of the American Society of Gene Therapy. 2008; 16(9):1556-1564. [PubMed: 18665158] 
96. Phuong LK, Allen C, Peng KW, et al. Use of a vaccine strain of measles virus genetically engineered to produce carcinoembryonic antigen as a novel therapeutic agent against glioblastoma multiforme. Cancer research. 2003; 63(10):2462-2469. [PubMed: 12750267]

97. Myers R, Harvey M, Kaufmann TJ, et al. Toxicology study of repeat intracerebral administration of a measles virus derivative producing carcinoembryonic antigen in rhesus macaques in support of a phase I/II clinical trial for patients with recurrent gliomas. Human gene therapy. 2008; 19(7): 690-698. [PubMed: 18576918]

98. Brown MC, Gromeier M. Cytotoxic and immunogenic mechanisms of recombinant oncolytic poliovirus. Current opinion in virology. 2015; 13:81-85. [PubMed: 26083317]

99. Gromeier M, Alexander L, Wimmer E. Internal ribosomal entry site substitution eliminates neurovirulence in intergeneric poliovirus recombinants. Proceedings of the National Academy of Sciences of the United States of America. 1996; 93(6):2370-2375. [PubMed: 8637880]

100. Gromeier M, Lachmann S, Rosenfeld MR, Gutin PH, Wimmer E. Intergeneric poliovirus recombinants for the treatment of malignant glioma [see comments]. Proceedings of the National Academy of Sciences of the United States of America. 2000; 97(12):6803-6808. [PubMed: 10841575]

101. Ochiai H, Moore SA, Archer GE, et al. Treatment of intracerebral neoplasia and neoplastic meningitis with regional delivery of oncolytic recombinant poliovirus. Clinical cancer research : an official journal of the American Association for Cancer Research. 2004; 10(14):4831-4838. [PubMed: 15269159]

102. Dobrikova EY, Goetz C, Walters RW, et al. Attenuation of neurovirulence, biodistribution, and shedding of a poliovirus:rhinovirus chimera after intrathalamic inoculation in Macaca fascicularis. Journal of virology. 2012; 86(5):2750-2759. [PubMed: 22171271]

103. Nisole S, Saib A. Early steps of retrovirus replicative cycle. Retrovirology. 2004; 1:9. [PubMed: 15169567]

104. Tai CK, Kasahara N. Replication-competent retrovirus vectors for cancer gene therapy. Front Biosci. 2008; 13:3083-3095. [PubMed: 17981778]

105. Tai CK, Wang WJ, Chen TC, Kasahara N. Single-shot, multicycle suicide gene therapy by replication-competent retrovirus vectors achieves long-term survival benefit in experimental glioma. Molecular therapy : the journal of the American Society of Gene Therapy. 2005; 12(5): 842-851. [PubMed: 16257382]

106. Wang W, Tai CK, Kershaw AD, Solly SK, Klatzmann D, Kasahara N, Chen TC. Use of replication-competent retroviral vectors in an immunocompetent intracranial glioma model. Neurosurg Focus. 2006; 20(4):E25. [PubMed: 16709031]

107. Perez OD, Logg CR, Hiraoka K, et al. Design and selection of Toca 511 for clinical use: modified retroviral replicating vector with improved stability and gene expression. Molecular therapy : the journal of the American Society of Gene Therapy. 2012; 20(9):1689-1698. [PubMed: 22547150]

108. Ostertag D, Amundson KK, Lopez Espinoza F, et al. Brain tumor eradication and prolonged survival from intratumoral conversion of 5-fluorocytosine to 5-fluorouracil using a nonlytic retroviral replicating vector. Neuro-oncology. 2012; 14(2):145-159. [PubMed: 22070930]

109. Huang TT, Hlavaty J, Ostertag D, et al. Toca 511 gene transfer and 5-fluorocytosine in combination with temozolomide demonstrates synergistic therapeutic efficacy in a temozolomide-sensitive glioblastoma model. Cancer gene therapy. 2013; 20(10):544-551. [PubMed: 23969884]

110. Huang TT, Parab S, Burnett R, et al. Intravenous administration of retroviral replicating vector, Toca 511, demonstrates therapeutic efficacy in orthotopic immune-competent mouse glioma model. Human gene therapy. 2015; 26(2):82-93. [PubMed: 25419577]

111. Hastie E, Grdzelishvili VZ. Vesicular stomatitis virus as a flexible platform for oncolytic virotherapy against cancer. J Gen Virol. 2012; 93(Pt 12):2529-2545. [PubMed: 23052398]

112. Stojdl DF, Lichty BD, tenOever BR, et al. VSV strains with defects in their ability to shutdown innate immunity are potent systemic anti-cancer agents. Cancer cell. 2003; 4(4):263-275. [PubMed: 14585354] 
113. Lun X, Senger DL, Alain T, et al. Effects of intravenously administered recombinant vesicular stomatitis virus (VSV(deltaM51)) on multifocal and invasive gliomas. Journal of the National Cancer Institute. 2006; 98(21):1546-1557. [PubMed: 17077357]

114. Muik A, Stubbert LJ, Jahedi RZ, et al. Re-engineering vesicular stomatitis virus to abrogate neurotoxicity, circumvent humoral immunity, and enhance oncolytic potency. Cancer research. 2014; 74(13):3567-3578. [PubMed: 24812275]

115. Wollmann G, Drokhlyansky E, Davis JN, Cepko C, van den Pol AN. Lassa-vesicular stomatitis chimeric virus safely destroys brain tumors. Journal of virology. 2015; 89(13):6711-6724. [PubMed: 25878115]

116. van den Pol AN, Davis JN. Highly attenuated recombinant vesicular stomatitis virus VSV-12'GFP displays immunogenic and oncolytic activity. Journal of virology. 2013; 87(2): 1019-1034. [PubMed: 23135719]

117. Obuchi M, Fernandez M, Barber GN. Development of recombinant vesicular stomatitis viruses that exploit defects in host defense to augment specific oncolytic activity. Journal of virology. 2003; 77(16):8843-8856. [PubMed: 12885903]

118. Wollmann G, Rogulin V, Simon I, Rose JK, van den Pol AN. Some attenuated variants of vesicular stomatitis virus show enhanced oncolytic activity against human glioblastoma cells relative to normal brain cells. Journal of virology. 2010; 84(3):1563-1573. [PubMed: 19906910]

119. Chan WM, McFadden G. Oncolytic Poxviruses. Annu Rev Virol. 2014; 1(1):119-141. [PubMed: 25839047]

120. Bartee E, McFadden G. Human cancer cells have specifically lost the ability to induce the synergistic state caused by tumor necrosis factor plus interferon-beta. Cytokine. 2009; 47(3): 199-205. [PubMed: 19640730]

121. Wang G, Barrett JW, Stanford M, et al. Infection of human cancer cells with myxoma virus requires Akt activation via interaction with a viral ankyrin-repeat host range factor. Proceedings of the National Academy of Sciences of the United States of America. 2006; 103(12):4640-4645. [PubMed: 16537421]

122. Lun X, Yang W, Alain T, et al. Myxoma virus is a novel oncolytic virus with significant antitumor activity against experimental human gliomas. Cancer research. 2005; 65(21):99829990. [PubMed: 16267023]

123. Lun X, Alain T, Zemp FJ, et al. Myxoma virus virotherapy for glioma in immunocompetent animal models: optimizing administration routes and synergy with rapamycin. Cancer research. 2010; 70(2):598-608. [PubMed: 20068158]

124. Zemp FJ, Lun X, McKenzie BA, et al. Treating brain tumor-initiating cells using a combination of myxoma virus and rapamycin. Neuro-oncology. 2013; 15(7):904-920. [PubMed: 23585629]

125. McKenzie BA, Zemp FJ, Pisklakova A, et al. In vitro screen of a small molecule inhibitor drug library identifies multiple compounds that synergize with oncolytic myxoma virus against human brain tumor-initiating cells. Neuro-oncology. 2015; 17(8):1086-1094. [PubMed: 25605818]

126. Kaur B, Cripe TP, Chiocca EA. "Buy one get one free": armed viruses for the treatment of cancer cells and their microenvironment. Curr Gene Ther. 2009; 9(5):341-355. [PubMed: 19860649]

127. Agarwalla P, Barnard Z, Fecci P, Dranoff G, Curry WT Jr. Sequential immunotherapy by vaccination with GM-CSF-expressing glioma cells and CTLA-4 blockade effectively treats established murine intracranial tumors. Journal of immunotherapy. 2012; 35(5):385-389. [PubMed: 22576343]

128. Wainwright DA, Chang AL, Dey M, et al. Durable therapeutic efficacy utilizing combinatorial blockade against IDO, CTLA-4, and PD-L1 in mice with brain tumors. Clinical cancer research : an official journal of the American Association for Cancer Research. 2014; 20(20):5290-5301. [PubMed: 24691018]

129. Dias JD, Hemminki O, Diaconu I, et al. Targeted cancer immunotherapy with oncolytic adenovirus coding for a fully human monoclonal antibody specific for CTLA-4. Gene therapy. 2012; 19(10):988-998. [PubMed: 22071969]

130. Engeland CE, Grossardt C, Veinalde R, et al. CTLA-4 and PD-L1 checkpoint blockade enhances oncolytic measles virus therapy. Molecular therapy : the journal of the American Society of Gene Therapy. 2014; 22(11):1949-1959. [PubMed: 25156126] 
131. Van Gool SW. Brain Tumor Immunotherapy: What have We Learned so Far? Frontiers in oncology. 2015; 5:98. [PubMed: 26137448]

132. Yin D, Zhai Y, Gruber HE, et al. Convection-enhanced delivery improves distribution and efficacy of tumor-selective retroviral replicating vectors in a rodent brain tumor model. Cancer gene therapy. 2013; 20(6):336-341. [PubMed: 23703472]

133. Nakashima H, Kaur B, Chiocca EA. Directing systemic oncolytic viral delivery to tumors via carrier cells. Cytokine \& growth factor reviews. 2010; 21(2-3):119-126. [PubMed: 20226717]

134. Young JS, Kim JW, Ahmed AU, Lesniak MS. Therapeutic cell carriers: a potential road to cure glioma. Expert Rev Neurother. 2014; 14(6):651-660. [PubMed: 24852229]

135. Ahmed AU, Thaci B, Tobias AL, et al. A preclinical evaluation of neural stem cell-based cell carrier for targeted antiglioma oncolytic virotherapy. Journal of the National Cancer Institute. 2013; 105(13):968-977. [PubMed: 23821758]

136. Duebgen M, Martinez-Quintanilla J, Tamura K, Hingtgen S, Redjal N, Wakimoto H, Shah K. Stem cells loaded with multimechanistic oncolytic herpes simplex virus variants for brain tumor therapy. Journal of the National Cancer Institute. 2014; 106(6):dju090. [PubMed: 24838834]

137. Yong RL, Shinojima N, Fueyo J, et al. Human bone marrow-derived mesenchymal stem cells for intravascular delivery of oncolytic adenovirus Delta24-RGD to human gliomas. Cancer research. 2009; 69(23):8932-8940. [PubMed: 19920199]

138. Fulci G, Breymann L, Gianni D, et al. Cyclophosphamide enhances glioma virotherapy by inhibiting innate immune responses. Proceedings of the National Academy of Sciences of the United States of America. 2006; 103(34):12873-12878. [PubMed: 16908838]

139. Kolb EA, Sampson V, Stabley D, et al. A phase I trial and viral clearance study of reovirus (Reolysin) in children with relapsed or refractory extra-cranial solid tumors: a Children's Oncology Group Phase I Consortium report. Pediatr Blood Cancer. 2015; 62(5):751-758. [PubMed: 25728527] 
Table 1

Recently completed or ongoing clinical trials using OVs in malignant glioma patients.

\begin{tabular}{|c|c|c|c|}
\hline Therapy name & $\begin{array}{l}\text { Name of } \\
\text { OVs }\end{array}$ & Dosing regimen & Reference \\
\hline HSV1716 & HSV & $\begin{array}{l}\text { Single injection }\left(1 \times 10^{5}-10^{7} \mathrm{pfu}\right) \text { into or near the } \\
\text { tumor resection cavity. }\end{array}$ & NCT02031965 \\
\hline G47 & HSV & $\begin{array}{l}\text { Stereotactic administration of assigned dose into } 2- \\
5 \text { different coordinates; administration of same } \\
\text { dose at the same coordinates 5-14 days later. }\end{array}$ & WHO JPRN-UMIN000002661 \\
\hline M032 (hIL-12) & HSV & $\begin{array}{l}\text { Single injection into the tumor; highest safe dose if } \\
\text { no dose-related toxicity observed. }\end{array}$ & NCT02062827 \\
\hline \multirow[t]{2}{*}{ Delta-24-RGD-4C (DNX2401) [DNAtrix] } & Ad & $\begin{array}{l}\text { Group 1: Intratumoral dose escalating from } 1 \times 10^{7} \\
\text { to } 3 \times 10^{10} \text { vp. } \\
\text { Group } 2 \text { : Intratumoral dose-escalation followed by } \\
\text { surgical resection and administration of DNX2401 } \\
\text { into the resection cavity on day } 14 \text {. }\end{array}$ & NCT00805376 \\
\hline & & $\begin{array}{l}\text { Intratumoral convection-enhanced delivery of dose } \\
\text { escalating from } 1 \times 10^{7} \text { to } 1 \times 10^{11} \mathrm{vp} \text {. }\end{array}$ & NCT01582516 \\
\hline H-1PV (ParvOryx01) [Oryx GmbH] & PARVO & $\begin{array}{l}\text { Group } 1(\mathrm{n}=9) \text { : dose escalation from } 5 \times 10^{6} \text { to } \\
5 \times 10^{8} \text { pfu. Single intratumoral injection }(50 \%) \text {, } \\
\text { followed by another injection surrounding the } \\
\text { tumor resection cavity during tumor removal on } \\
\text { day } 10 \text {. } \\
\text { Group } 2(\mathrm{n}=9) \text { : Intravenous dose escalating from } \\
1 \times 10^{5} \text { to } 1 \times 10^{8} \text { pfu daily for } 5 \text { days followed by } \\
\text { same dose injected into the surrounding brain tissue } \\
\text { during tumor resection on day } 10 \text {. }\end{array}$ & $\begin{array}{c}(73) \\
\text { NCT01301430 }\end{array}$ \\
\hline Reolysin [Oncolytics Biotech Inc] & RV & $\begin{array}{l}10^{10} \mathrm{TCID}_{50} \text { injected as single intravenous infusion } \\
(\mathrm{n}=3) \text { on day } 1 \text {; three infusions on days } 1,2 \text { and } 3 \\
(\mathrm{n}=3) ; 5 \text { infusions from days } 1 \text { to } 5(\mathrm{n}=3) \text {. }\end{array}$ & ISRCTN 70443973 \\
\hline NDV-HUJ & NDV & $\begin{array}{l}\text { First part: dose escalation from } 0.1 \text { to } 11 \text { BIU } \\
\text { intravenously, followed by } 3 \text { injections of } 55 \text { BIU. } \\
\text { Second part: } 3 \text { doses of } 11 \text { BIU and then } 2 \text { doses of } \\
11 \text { BIU weekly. }\end{array}$ & (90) \\
\hline MV-CEA & MV & $\begin{array}{l}\text { Group 1: dose escalation from } 105 \text { to } 2 \times 10^{7} \\
\text { TCID50 administered into the resected cavity. } \\
\text { Group2: intratumoral injection followed by another } \\
\text { injectioninto the resected cavity on day } 5 \text {. }\end{array}$ & NCT00390299 \\
\hline PVS-RIPO & $\mathrm{PV}$ & $\begin{array}{l}\text { Convection-enhanced delivery of intratumoraldose } \\
\text { escalation from } 10^{8} \text { to } 10^{10} \operatorname{TCID}_{50}(\mathrm{n}=32) \text {. }\end{array}$ & NCT01491893 \\
\hline \multirow[t]{2}{*}{ Toca 511 [TocagenInc] } & MLV & $\begin{array}{l}\text { Single stereotactic injection into the tumor, } 3-4 \\
\text { weeks later administration of oral } 5 \text {-FC ( } 120 \mathrm{mg} \text { or } \\
300 \mathrm{mg} / \mathrm{kg} / \text { day) (6-day cycle every month) } \\
\text { repeated } 6 \text { times. }\end{array}$ & NCT01156584 \\
\hline & & $\begin{array}{l}\text { Dose escalation and injection of Toca } 511 \text { into the } \\
\text { resection cavity, } 7 \text { weeks later three repeats of oral } \\
5 \text {-FC ( } 8 \text {-day cycle) every } 2 \text { months }\end{array}$ & NCT01470794 \\
\hline
\end{tabular}

Drugs Future. Author manuscript; available in PMC 2016 February 05. 